\title{
Masters of the Screen: On Media Warfare, Optics, and Photography as Fatal Strategy
}

\author{
Rebecca Lee Sanchez \\ European Graduate School \\ Seewjinenstrasse 6, $\mathrm{CH}-3930$ Visp \\ RebeccaLeeSanchez@gmail.com
}

\begin{abstract}
Departing from Bernard Harcourt's The Counterrevolution, this paper considers how American counterinsurgency theory-based government and paramilitarizated optics together created Baudrillard's "irruption of the obscene"-where Rapid Dominance strategy bleeds across the delineation between military and civilian realms, where mass media becomes the site of warfare-and re-examines Rapid Dominance along these new terms: when loss of illusion unfolds alongside declarations of "transparency" and "truth," when everything becomes optics as mediated by a screen-the limits of which we can no longer detect-there can be no visual comprehension of our environment. Here, the strategy continues to issue a condemnation-to-paralysis, a being-ensnared in the cyclical effects of vertigo and fascination within the trance of spectatorship, but who is the new adversary? How is the field of vision renegotiated and what is camouflage? Disrupting our visual hypnosis, this paper uses Baudrillard's Fatal Strategies alongside Virilio's Vision Machine to argue that resistance is still possible-the faculties of battlefield-perception can be wrenched back - presenting visual communication as weapon against the omnipotence of Rapid Dominance: a new photographic language through technological manipulation that breaks the flow of information, refracts shock and awe and puts on display our full monstrosity as the pharmakon of perception.
\end{abstract}

Media, Optics, Rapid Dominance, Virality, Virtual, Information, Truth, Reality, Photography, Fatal Strategies

\section{AN AGITATED PACIFICATION}

Black holes. Found all over, these invisible gaping maws, demiurgic functionaries of our universe, have a deceptive impresence. They are space stalkers known to sometimes rupture the calm of nothingness by ripping "passing stars in half and scattering their remains." Ever loyal to the cycles of life and creation, we understand new black holes as emerging from this debris. Supermassive black holes - believed by astronomers to be located in the center of every galaxy, like our Sagittarius $A^{*}$ - are black holes of the largest order. Monster masses of consumption, their presumed but otherwise imperceptible locations are betrayed by their voracious appetites - growing by accretion (i.e. gravitational attraction of as yet more matter). The diffused material and gases sucked into their gravitational pull make up the "churning, hellish, hot-and-cold gas storms "ii that spiral toward an awaiting orifice. This cosmic omen was recently rediscovered by scientists to be not merely orbital, but more like a fountain: a constant stream of cold gas sinking toward ingestion. Some of that gas gets superheated by its proximity to the hole and spit back into space where it either escapes as a sort of centrifugal flare, a divergence, or "still in the thrall of the black hole's gravity, curves back around and re-enters the falling stream."iii And so it is that the supermassive black hole comes to be both a terrific destructive force and the artificer of new life and worlds. This is today our departure point. Let me explain how we got here.

The American news media, in grappling with the ruptures all around us-the shattering of our national and local politics, breakdowns in discourse and extreme polarization, webs of 
international interferences, the total overgrowth of social media, the "rise" of misinformation, mistrust, general discord, and the implications of such civilizational excrescences on our flailing industry, evermore poor in both cash and confidencehas struggled to locate a reference point or construct a mode of understanding, much less a strategy of transmission. Whether we are living in what Jean Baudrillard called the "irruption of the obscene," what Alexis de Tocqueville predicted could become the "tyranny of the majority," what Siegfried Kracauer in a 1927 assessment of the spread of photography via the newly emerging American magazine industry referred to as an "assault so powerful that it threatens to destroy the potentially existing awareness of crucial traits," one thing is clear-we are all implicated in an improvisational cooperation toward the breeding and festering of fears, individual and collective. We are ourselves the heralds of derangement, infiltrating our own worlds and thrusting them into seizure.

"Never before," Kracauer wrote," has an age been so informed about itself, if being informed means having an image of objects that resembles them in a photographic sense... Never before has a period known so little about itself.,iv

This oblivion of transparency - a paralysis by excess-is furthermore disfigured by a gluttony for truth with which we gorge ourselves until we choke on regurgitated veracity. We have not yet come to understand, as E.M. Cioran says, that "our truths are worth no more than those of our ancestors," that "the devil pales beside the man who owns a truth, his truth." And that, the only way forward with any "intellectual decency" is to "banish [that] enthusiasm for civilization" which has so often been the impetus toward genocide and ruin. ${ }^{\vee}$

Our current disorientation-this state of agitated pacification-is, however, not one we have reached on our own. For it is indeed the case that sheep need their shepherds, and the wolves are never far.

In his newest book, The Counterrevolution: How Our Government Went to War Against Its Own Citizens, lawyer and Columbia professor Bernard E. Harcourt, unravels a chronology of militarization and propagandizing that traces the rise of a domestic counterinsurgancywithout-insurgancy-a governmental counterrevolution that knows no unified enemy, combats no adversaries linked arm in arm, in seething revolutionary spirit, but sees its foe in each citizen, now its target. It begins after 9/11 with a sharp pivot in foreign policy and the national security exchange economy. While abroad drone strike campaigns started by George W. Bush ripened into an unpreceented scourge of the skies under Barack Obama, special operations, torture and indefinite detention invaded territories outside of traditional and official war zones-that is to say, outside the legal body, coordinates that became terrestrial appendages to it at best. Militarized police and mass surveillance desecrated everything from roadway deathsites in places like Ferguson Missouri, to unsuspecting mosques in New York City, and the "right" to privacy assumed in the use of mobile phones at home-events that more and more came to be captured by, transmitted and mediated through, and eventually, disappeared into, our cripplingly reliable screens. It is this systematic, contrived counterinsurgency with its insistence on a paramilitarized politics (and I would argue optics) and, through it, the pacification of a people that, Harcourt argues, has worked to create the state 2019 America is in.

In short, we have witnessed and been played by nothing less than the real-time collapse of the political scene (a slow disintegration over a much longer stretch of time than we're willing to admit, recently made more visible by its acceleration). We were for a time left to navigate the running rampant of political theater, each of us, inescapably, as actors in the irruption of the obscene, always fearing the next fallout, a final catasrophe to spell the end. But we are today in a space far beyond the technologically instigated and mass media sustained unreality of the Gulf War. Rapid Dominance has bled across the delineation between military and civilian realms, tearing the regime of shock and awe down from the drones overhead and in from outdated and long-abandoned trenches, toward that other extermination. That other dimension altogether that Baudrillard presents in The Double Extermination: an essentially perpetual twilight of absurdity where there can be no end, where objective reality disappears into the hallucinations of the virtual, everything runs out its course in a state of simultaneity, acts can no longer find their meaning, effects their cause. Lost to "crepuscular passion," the dimension of Real-Time is the void beyond the end, which nothing can penetrate without losing its substance, as Baudrillard tells us, and in which no event ever comes to pass. ${ }^{\text {vii }}$ We exist always on the brink of a catastrophe 
which cannot finally take place: nuclear uncertainty with North Korea, war with Iran, trade collapses with China, Mexico, Canada. Fallout after fallout, without any fallout, only repetition of the same-loops, feeds, revolving around the nothing that must be dislodged.

For weeks news reports and outrage revolved vigorously around the impending fate of U.S. Attorney General William Barr, waiting each moment to learn whether or not he would be held in contempt for his role in the unraveling of the Trump administration. The New York Times morning briefings, three weeks after the first headling, were still leading with the uncertainty of William Barr's fate. We can now miss everything without missing anything at all, and yet, our fear of missing out-our "\#FOMO"-has never been greater.

Ours is no longer a question about the involvement of the mass-media in this warfare, but the recognition that mass-media is now the site of warfare, and not merely as the capital-E "Enemy" of the little-p "people," Jim Acosta against the White House, op-eds in the Washington Post, "Fake News," Twitter bot, Facebook misinformation, Whatsapp rumor sense. We are all mass media-you, me, audience, object, content, product and consumer-trapped in the circular motion of a feed that can never end, constantly reproducing ourselves for sale and selfcannibalizing. Doubling, multiplying-each of us a story of cell division, splitting off into virtual clone after virtual clone like the army of a modern day Raktabija - the hindu demon whose blood-seed reproduces itself on the very spot onto which any trickling droplet falls, making him impossible to overcome, save for the swift tongue of the Goddess Kali. It is, in the end, this slopping oral muscle that becomes executioner.

In this way, what Manuel DeLanda more literally described as the eventual human/machinic transmutation toward one self-replicating phylogenetic line has already today taken place. DeLanda's robot historian is already here in the algorithmic anti-fleshnot using humans as "no more than pieces of a larger military-industrial war machine," "viii but puppeteering a merging in which one becomes indistinguishable from the other as both war machine and battlefield. The corpse has been swallowed by the virtual, which today, like any good puppeteer, manipulates the body-laidwaste to create the illusion of that which is alive. It was also in The Double Extermination that Baudrillard declared "Today we do not think the virtual, the virtual thinks us." Indeed, it is today only the virtual that, without even being able to fathom illusion, both sustains and shatters it in an epic mastery of algorithmic duality. And we, in our collective stupefaction, have altogether lost sight beyond the screen. Illusion is no longer conjured by man, but by the virtual over man. In its final stage, this viral transmutation takes its place in a landscape of disembodied violence that wells up not from the viscera-from passion or instinct-but from the screen. It is not an enthusiastic violence but a prolific one. And what is to be feared, Baudrillard notes, is not its psycological spread but the technological extension of this violence, which dooms us, in a state of loss, to hatred, and the real in a state of loss to the virtual, to Baudrillard's "curse of the screen." It is a violence not of the message, but the medium-the leading effect of which is the apoplectic contractions of time which operate as a turniquet, each jolt constricting an already strangled global population, a paradox inherent in the sudden expansion of accessibility. A vastness that is also the trigger for deoxygenation, claustrophobia.

In this delirium-under the domination of a counterinsurgency filtered through the virtualwhere the regime of shock and awe continues to issue a condemnation-to-paralysis, a beingensnared resulting from our collective captivation with terror and the cyclical effects of vertigo and fascination in the trance of spectatorship, we attempt to reinforce a hyperindividuality within a larger situational anonymity. In the administration of fear as a tactic for governing, it is as Virilio sees it, a fragmentation that "continues to deepen, all the way to the egotism and solitude of the subject, which goes along with the mass individualism that has become our sociological state." In the disappearance of identity and the masking of that disapperance, we cry out our respective "truths" fortify our respective "narratives," when it is precisely the opposite impulse we should indulge, in the image of the late Butoh master Kazuo Ohno: to become "the creature of the world, he who has no identity, he who existed before the appearance of the individual. Then all is but a game."

Here, the only possibility in order to remain a contender is to disappear, become more invisibile than the invisible, to camouflage, as we do, in our profusion of images in which there is nothing to see-fatal strategy of the surface, toward a more profound obliteration of the notion of the reality of the real. We must 
take on the face of another, the face of every other, in the spirit of Kobo Abe, who warned that to cling too closely to reality is to risk that the result may well be far from realistic. We might take our cue from $\mathrm{Al}$ influencers who thrive on Instagram, fooling entire masses despite always keeping intact a single giltchthe trace that anchors it to its unreality. A necessary breadcrumb along the path to recalling our sense of illusion: an asymmetry, a mutation of proportion, a black hole left vacant by the truancy of information.

Because the loss of illusion has unfolded alongside declarations of "transparency" and "truth," we must renegotiate these concepts. It's a sign of the times we're in when the most simple and complete understanding, as I see it, of what we are today navigating can be found on the wall of Walt Disney World's Splash Mountain.

On a day trip to the Magic Kingdom, I boarded a log and bobbed along a creek, through a "dark ride" following a trickster tale on the dangers of a hare leaving home to chase adventure. When the hare returns, having realized he should have never ventured out of his patch, his lesson has been learned and the words scrawled along the walls to welcome him home read: "It's the truth. It's actual. Everything is Satisfactual" - the inherent warning here being that the truth is malleable - it is legion, truths are many and they are none, providing the conditions for what I will henceforth call the utopia of carefully fortified "social media cocoons" of like-mindedness and delusion distillation. And truths in the hands of believers have ne'er been a more grave danger.

We as the agents of mass media are currently swimming against the rip current in this sea of global disruption and, amidst all that disruption, are counting on traditional, ineffective means for staying afloat. The current state of our every day and its potential worsening - whether you call it a circus, alternative fact, an unreality - has formed a behemoth supermassive black hole, and we are the diffused material churning wildly in the aforementioned "hellish hot-and-cold gas storms" at once wielding the power to feed or betray our fate. But our appetite, both as a people with a ravenous hunger to consume everything all the time, and as content makers with a hunger to feed the 24/7 machine that will satisfy our own demand, will grow the hole and spell our end.
Paramilitarized optics are no longer purely visual but multisensory, and in our bewildered atrophy we know only how to receive them with bad digestion. We live only in relation to the virtual, through the screen-the perimeters of which we can no longer detect-and there can be no visual comprehension of our environments as our mass hysteria exacerbates an increasingly more deterritorialized, global contagion from which space and time in this new order must be dislodged in order to break free from the smothering of the contraction.

In our current state, according to my industry peer, Luke O'Neil, who in December wrote a prediction for the Harvard Nieman Lab on the way journalism will go in $2019^{\mathrm{xi}}$, the last remaining source of local news and, as such, a form of contact with a kind of concrete reality, are neighborhood-based Facebook groups. But even these, he says, have been sullied by the inability to differentiate truth from fiction, decency and lewdness, explaining that this is actually a place that will be either for questions about what night of the week allows for street parking or whether or not rumors about "the mayor's horse-fucking dungeon" are real. But the third option remains that we are already in a state where this is the site for both of those inquiries simultaneously, because the playing field of possibility has been leveled and we can no longer delineate what is legitimate and what isn't, where truths and tales come from or where to go with them. The lines and sources and realities have been blurred, information made true to satisfy what we want to be true - "alternative facts," "Satisfactuals." Absurdity has set in and we are all the cow being thrown across the sky in Twister. It is a climatic calamity that beckons a "Fatal Strategy"-a self-destructive reimagining of our relationship to our screens and the misinformation and propaganda that emerge from them. It is time for an astral twitch that spits our particles away from the black hole, out into space, and into a different course where we might enter into a new gravitational pull and form the basis of a new world.

It is here that a resistance is still possible-the faculties of battlefield-perception currently lost in the haze of strategies of deception and pacification, arrested by the virtual, can be wrenched back to the domain of human vision-whatever its limitations, if only we accept this trajectory which ultimately leads us to a final confrontation: our reality is not real, and it is precisely this that will save it. 
Working toward a disruption of our visual hypnosis, we must take seriously the possibility of a new photographic language as a deliberate infliction of an anamorphic Troxler Effect.

\section{PHOTOGRAPHY AS FATAL STRATEGY}

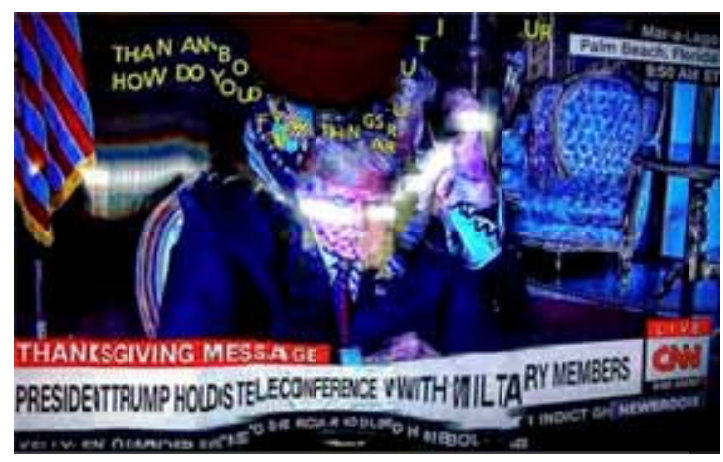

Figure 1. How do you find things are?

The images presented here are a response to the last line of Baudrillard's essay The Powerlessness of the Virtual, in which he says there are no masters of the universe, only masters of transparency, to which I push further and pair the notion of transparency with Paul Virilio's notion of "Trans Apparency" - to arrive at the conclusion that the only remaining masters are those of the screen.

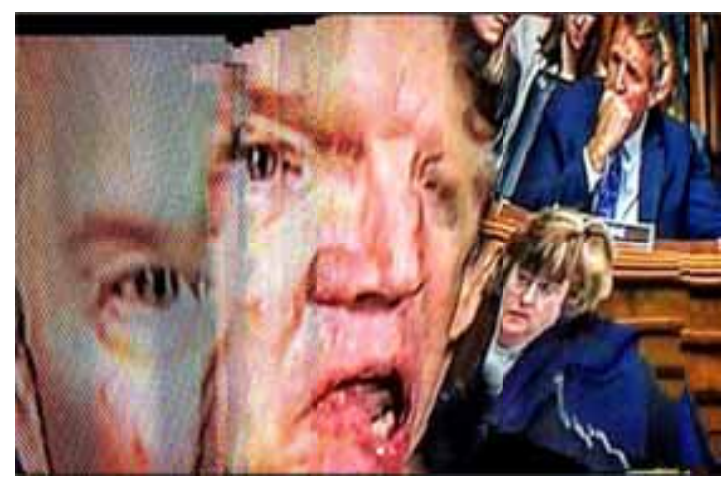

Figure 2. Of Saints and Hysterics

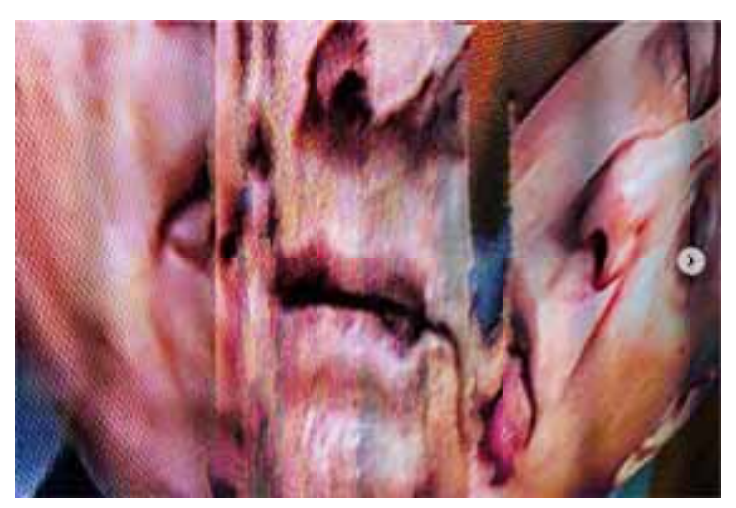

Figure 3. Dribble

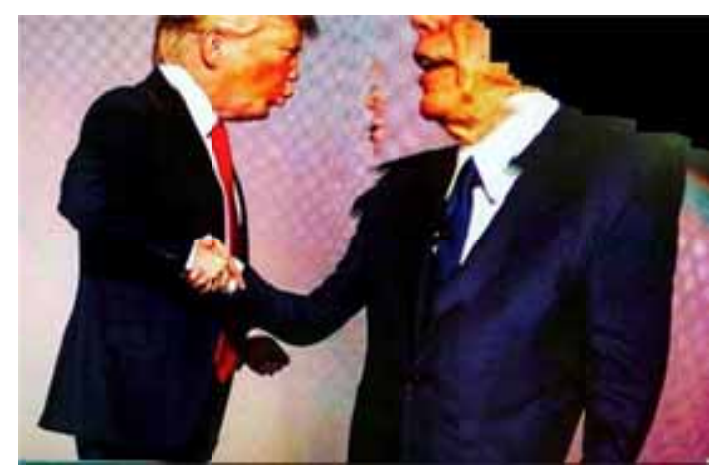

Figure 4. Mouths and Money

This is the departure point for Masters of the Screen: an visual art project that uses technological manipulation as the method toward this new photographic language through which to examine the "irruption of the obscene"- that of everything that is determinedly "filmed, filtered, reviewed and corrected under the wide-angle lens of the social, of morality, and information..." the "truer than true"-and the passage of the real into pornographic hyperreality, into the virtual. This work is an ongoing examination of politics and spectatorship as mediated by the screen, the game of news media-information distribution and consumption, our collective captivation with terror and the resulting vertigo. It is intended to feed the excesses of the obscene into the place beyond, the virtual, until the only remaining options are collapse or reversal. Because only then can we begin to think anew. It is a photography of the screen geared toward making monsters of the monstrous by warping photographs and television news broadcasts to an almost unrecognizable degree, in order to shatter the hope for intelligibility and meaning while simultaneously reminding the spectator that something does still remain beyond the image. This is not a work made in post-production-it is not Photoshopped. It is not accidental or arbitrary Glitch Art. Instead, it uses solely the iPhone panoramic camera app to make images that "break" the flow of information, mimicking our own broken modes of consumption and ingestion of broken information, reminding the viewer of its surface value and the presence of the screen. It is a learned manipulation of the camera app to capture this visual information in deliberately broken or distorted ways, while preventing the camera from shutting down completely, which is its automatic response if it senses it has not captured the information correctly. Each deformity is meant to introduce an idea, a puzzle piece toward reconfiguring illusion. 


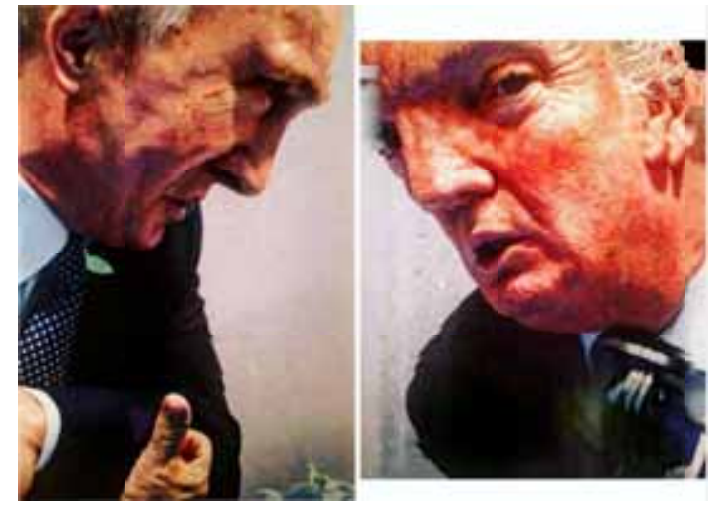

Figure 5. Official Tryst

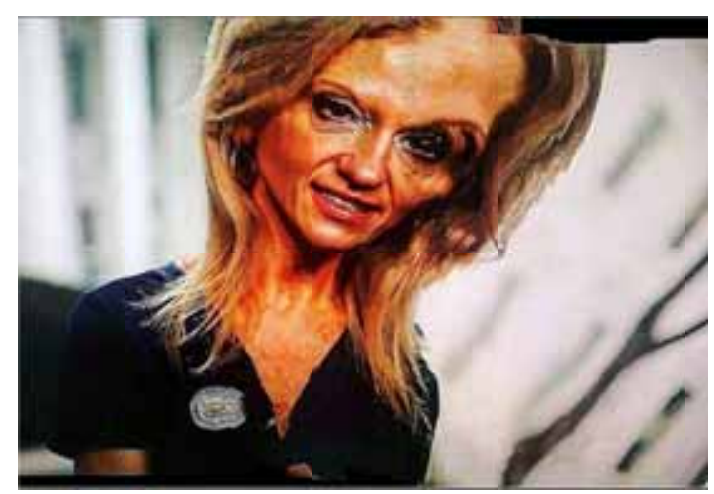

Figure 6. Alternative Kelly

As a photographic strategy, the images are then printed in as small a format as possible, in an attempt to disrupt and implicate the viewer in the act of viewing. Weaponizing Monet as a stylistic tactic, the images wrench the eyes away from this metaphysical nearsightedness in a world where seeing is believing, forcing one to see into the distance-breaking, even momentarily, the spell of a screen-induced mobile immobility, and compelling the viewer to shift positionscoming nearer, stepping back, stepping outin order to bring into focus details which betray the breadcrumbs that lead back to illusion.

At once a criticism of our politics, our news media, our obsessions with deciphering, and our society, these photographs are a commentary on both how we are looking but not seeing, and what it is that is not being seen.

They serve as a "fatal strategy against the pacification of existence"-that functions, at once, as a confrontation and a perpetration, a distended suspension of time to counter the tourniquet of the 24-hour social and information machines, a hostage taking-of meaning, of ourselves as the viewer, and as the players-an act of terror and one of seduction, a visual synecdoche, a play between metastatic ecstasy and ecstatic metastasis, a destruction of and solicitation for meaning - both against our obsession with deciphering reality, and toward ambiguity as protest-a construction of Maurice Blanchot's absolute, unyielding distance, an apparatus for catastrophe, commanding the viewer to think beyond the optics of and for the screen as the establishment of the nothing-disruption for the sake of restoring radical illusion via disgust and repulsion - to quench the desire for both the abject and our entrancement with this solitary sensorial distortion, a treacherous flirtation which casts the last stirring of defiance into the darkness only to disintegrate, a deliberate technological manipulation which efforts to break the flow of information, refract shock and awe and put on display our full monstrosity as the pharmakon of perception. What is necessary is visual communication as a weapon for dismantling institutions of power-specifically, for crippling the omnipotence of counterinsurgency theorybased governing, and betraying the curse of the virtual-as an affront to "the transparency and obscenity of information in a universe emptied of event, the transparency and obscenity of space in the promiscuity of networks, transparency and obscenity of the social in the masses, of the political in terror, "xii because, as Baudrillard says, "these are the stakes. There are no others."

\section{REFERENCES}

DeLanda, M.

(1991) War in the Age of Intelligent Machines. Zone Books, New York.

Harcourt, B.E.

(2018) The Counterrevolution: How Our Government Went to War Against its Own Citizens. Basic Books, New York.

Baudrillard, J.

(2002) Screened Out. Verso, New

York.

Baudrillard, J.

(1983) Fatal Strategies. Semiotext(e), New York.

Cioran, E.M

(1975) A Short History of Decay. Arcade Publishing, New York.

Kracauer, S., Levin, T.

(1993) Photography. Critical Inquiry, Vol. 19 (Spring). 421-436. 
Virilio, $P$.

(2012) The Administration of Fear.

Semiotext(e), New York.

Virilio, $P$.

(1994) The Vision Machine. Indiana University Press, Indiana.

\footnotetext{
'Mann, A. (2018) How Does a Black Hole Form? LiveScience. Available from: https://www.livescience.com/63436-IIm-howblack-holes-form.html
}

Letzter, R. (2018) Astronomers Think They've Figured Out the Raging Swirls of Gas Around Supermassive Black Holes LiveScience. Available from: https://www.livescience.com/64248-blackhole-fountain.html

iii ibid. Letzter

iv Kracauer, S., Levin, T. (1993) Photography. Critical Inquiry, Vol. 19 (Spring). 432.

$\checkmark$ Cioran, E.M. (1975) Genealogy of Fanaticism. In: Howard, R. (tr). A Short History of Decay. New York: Arcade Publishing. 3-6.

vi Baudriallard, J. (2002) Disembodied Violence: Hate. In: Turner C. (tr). Screened Out. New York: Verso. 94.

vii Baudrillard, J. (2002) The Double Extermination. In: Turner, C. (tr). Screened Out. New York: Verso. 107-111.

viii DeLanda, M. (1991) Introduction. In: War in the Age of Intelligent Machines. New York: Zone Books. 3.

ix Baudrillard, J. (2002) 'Lost from View' and Truly Disappeared. In: Turner, C. (tr). Screened Out. New York: Verso. 112-117.

$x$ Virilio, P. (2012) Administering Fear: Towards Civil Dissuasion. In: Richard, B. (ed). The Administration of Fear. New York: Semiotext(e). 51.

xi O'Neil, L. (2018) The End is Already Here. Harvard Nieman Lab. Available from: https://www.niemanlab.org/2017/12/the-end-isalready-here/

xii Baudrillard, J. (1983) The Obscene. In: Fleming, J. (ed). Fatal Strategies. New York: Semiotext(e). 50-70. 